\title{
Hemşirelik ögrencilerinin problem çözme becerilerinin incelenmesi
}

\author{
Nurcan UYSAL*, Buket MANAVOĞLU**
}

\section{ÖZET}

Amaç: Problem çözme birçok beceriyi içinde barındıran bir eylemdir ve öğrencinin derslerde başarılı olmasını olumlu yönde etkiler. Bu çalışma, hemşirelik öğrencilerinin problem çözme becerisi ve bu beceriyi etkileyebilecek faktörlerin belirlenmesi amacıyla yapılmıştır. Yöntem: Tanımlayıcı olarak planlanan araştırmanın verileri bir vakıf üniversitesinin hemşirelik bölümünde öğrenim gören toplam 104 öğrenciden elde edilmiştir. Verilerin toplanmasında sosyo-demografik veri formu ve 35 maddeden oluşan Problem Çözme Envanteri kullanılmıştır. Veriler sayı, yüzdelik, bağımsız gruplarda t test ve tek yönlü varyans analizi ile değerlendirilmiştir. Bulgular: Araştırmaya katılan öğrencilerin yaş ortalaması $19.64 \pm 1.41, \% 51$ 'i ikinci sınıf, \%88.5'i kızdır. Öğrencilerin Problem Çözme Envanteri puan ortalaması 117.3 \pm 17.3 olarak hesaplanmış ve problem çözme becerilerinin orta düzeyde olduğu belirlenmiştir. Öğrencilerin Problem Çözme Envanteri puan ortalamaları sosyodemografik özelliklere (Sınıf, cinsiyet, yaşanılan yer, anne ve babanın eğitim durumu, ekonomik durum) göre incelendiğinde gruplar arasında istatistiksel olarak anlamlı bir fark bulunmamıştır. Öğrencilerin akademik başarı durumları ile problem çözme becerileri puan ortalamaları arasında istatistiksel olarak anlamlı bir fark saptanmamıştır. Sonuçlar: Çalışma sonuçlarına göre hemşirelik öğrencilerinin problem çözme becerilerinin orta düzeyde olduğu belirlenmiştir. Hemşirelik mesleği hastaların sorunlarını çözmeye yönelik sürekli bir faaliyet içindedir. Bu nedenle öğrencilerin üniversite eğitimleri süresince problem çözme becerisini geliştirmeleri önemlidir. Hemşirelik müfredatında bu beceriyi kazandırmaya yönelik eğitimlerin planlanması ve interaktif eğitim yöntemlerinin kullanılması önerilmiştir.

Anahtar kelimeler: Hemşirelik, öğrenci, problem çözme

\section{The investigation of problem solving skills of nursing students}

\begin{abstract}
Objective: Problem-solving involves many skills and positively affects the student's success in their studies. The aim of this study is to determine the problem-solving skills of nursing students and the factors that may affect these skills. Methods: The data of this descriptive study was obtained from a total of 104 students in the nursing department of a foundation university. Socio-demographic data form and "Problem-Solving Inventory" consisting of 35 items were used to collect the data. The data were evaluated by number, percentage, independent samples $t$ test and one-way variance analysis test. Results: The mean age of the students is $19.64 \pm 1.41,51.0 \%$ of them were sophomore students and $88.5 \%$ of them were female. The mean score in Problem-Solving Inventory of the students was calculated as $117.3 \pm 17.3$ and the problem solving skills shows that problem solving skills of nursing students were moderate. When the average score of the students in Problem-Solving Inventory is examined according to sociodemographic characteristics (Class, gender, place of residence, education status of parents, economic status), there was no statistically significant difference between groups. There was no statistically significant difference between the students' academic achievement and problem solving skills scores. Conclusions: According to the results of the research, it was determined that problem solving skills of nursing students were moderate. The nursing profession is continuously developing to solve the problems of patients. Therefore, it is important that students develop problem solving skills during their university education. In the nursing curriculum, it is suggested trainings be planned and interactive training methods be used in order to make the students gain problem-solving skills.
\end{abstract}

Keywords: Nursing, student, problem-solving

\footnotetext{
Geliș Tarihi: 11.05.2019

Kabul Tarihi:22.06.2019

* Üsküdar Üniversitesi, Sağlık Bilimleri Fakültesi, Hemşirelik Bölümü, İstanbul, Türkiye, e-mail: uysalnurcan@ gmail.com nurcan.uysal@uskudar.edu.tr ORCID: 0000-0002-1325-9826

** Kent Hastanesi, Organ Nakil Bölüm Hemşiresi, İzmir, Türkiye, e-mail: buketmanavoglu@ @otmail.com ORCID: 0000-0002-8981-8305

Sorumlu Yazar / Correspondence: Nurcan Uysal uysalnurcan@gmail.com

Bu çalışma 22-26 Nisan 2015 yılında Kayseri'de yapılan 14. Ulusal Hemşirelik Öğrencileri Kongresi’nde poster bildiri olarak sunulmuştur.
}

Atıf: Uysal N, Manavoğlu B. Hemşirelik öğrencilerinin problem çözme becerilerinin incelenmesi. Sağlık ve Yaşam Bilimleri Dergisi 2019;1(1):1-5.

Citation:.Uysal N, Manavoglu B. The investigation of problem solving skills of nursing students. Journal of Health and Life Science 2019;1(1):1-5. 


\section{GíRIŞ}

Problem çözme bilinçli, akılcı, emek isteyen ve hedef odaklı bir etkinlik, 1,2 aynı zamanda "problemle başa çıkma" kavramıyla eş anlamlı" olarak kullanmıştır. ${ }^{3}$ Problem çözme becerisi, bireyin sürekli değişmekte olan dünya ile baş edebilmesi için yaratıc1, değişim yapabilme, araştırma yapma, analiz ve sentez etme gibi bilişsel beceri süreçlerinin etkileşiminden oluşmaktadır. ${ }^{4,5} \mathrm{Bu}$ becerilerin tümü, bireyin karşılaştığı problemlerde çözüme götürecek bilgileri kazanmasına ve kullanıma hazır olacak şekilde birleştirerek bir sorunu çözmesine neden olur. ${ }^{6}$ Hemşirelik eğitiminde ulaşılması gereken en temel hedeflerden birisi de budur. Çünkü hemşirelik bakım uygulamaları, bilginin kazanılması sonrasında analiz ve sentez yapilarak hastalarda var olan problemleri çözmek amaciyla planlanan ve süreklilik gerektiren aktivitelerdir. Farklı sorunları olan bireylere bakım veren ve klinik ortamda yaşanan çatışmaları çözmek durumunda olan hemşirelerin bu nedenle iyi düzeyde problem çözme becerisine sahip olması beklenmektedir. ${ }^{1}$ Problem çözme becerisi iyi olan hemşireler, bireylerin sağlığının korunması, geliştirilmesi, yaşam kalitesinin artırılmasında, kompleks sağlık sorunu olan hasta ve ailelerinin gereksinimlerini karşılamada ve bakımla ilgili rasyonel kararlar vermekte daha etkin davranmaktadırlar. ${ }^{2,7,8}$

Bireyin gelişimi, kendine güven, etkin iletişim becerisi, geçmiş yaşantı deneyimleri, duygu ve düşünceleri, motivasyonu, sosyokültürel yapısı, aldığı eğitim gibi birçok faktör bu problem çözme becerisinin gelişimine etki etmektedir. ${ }^{4,5,9}$ Yapılan bir çalışmada sosyal yaşamı aktif olan öğrencilerin karşılaştıkları sorunlarla daha iyi baş ettikleri belirlenmiştir. ${ }^{7}$ Kim ve Choi'nin ${ }^{10}$ yaptığı çalışmada, lisans düzeyinde, kişilerarası iletişimleri istendik düzeyde olan öğrencilerin problem çözme becerisinin daha iyi olduğu belirlenmiştir. Hemşirelik öğrencilerinin problem çözme becerilerinin yüksek olması hemşirelik eğitiminin önemli çıktılarından biridir. ${ }^{6}$ Ancak yapılan çalışmalar hemşirelik öğrencilerinin problem çözme becerilerinin geliştirilmesi gerekliliğini ortaya koymaktadır. Hemşirelik hizmetlerinde sağlık bakım problemlerinin giderek arttığ 1 , fakat çoğu hemşirelik öğrencilerinin klinik alanda yaşanan problemlere yönelik problem çözme becerilerinin farkında olmadıkları belirtilmiştir. ${ }^{5}$ Hemşirelik ve diğer lisans programlarındaki öğrencilerin problem çözme becerilerinin incelendiği çalışmaların metaanalizinde; Türkiye'de 2003-2015 yılları arasında yapılmış 31 çalışma incelenmiş ve bu çalışma sonuçlarında öğrencilerin problem çözme becerilerinin orta düzeyde olduğu saptanmıştır. ${ }^{11}$ Hemşirelik öğrencilerinin problem çözme alg1sı orta düzeyde bulunan bir çalışmada bunun nedenleri; eğitimde problem çözme becerisi kazandırmaya yönelik yöntemlerin kullanılmaması, eğiticilerin öğrencileri problem çözmeye teşvik etmede yetersiz kalması ve bu nedenle öğrencilerin bu beceriyi istenilen düzeyde kavrayamaması sonucunda problem çözme sürecini zor olarak görmelerinden kaynaklanabileceği bildirilmiştir. ${ }^{7}$ Literatürde yer alan çalışmalara göre, sistematik bir şekilde uygulanan problem çözme çalışmalarında hemşirelik öğrencilerinin zorlandığ $1{ }^{12}$ fakat geleneksel öğrenme yöntemlerine göre problem ya da vakalara dayalı aktif öğrenme yöntemlerinin kullanıldığı durumlarda öğrencilerin problem çözme düzeylerinin daha yüksek olduğu belirlenmiştir. ${ }^{13-15}$ Ançel $^{16}$ problem çözme eğitiminin hemşirelik öğrencilerinin problem çözme algısı üzerine etkisini belirlemek için yaptığı çalışmada, eğitimin beceri düzeyini geliştirmede etkili olduğunu saptamıştır.

Her birey farklı özellikler taşır ve bireylerin problem çözme becerilerini etkileyen çok çeşitli faktörler vardır. $\mathrm{Bu}$ nedenle öğrencilerin başarı durumlarının etkileyen faktörlerden birisi olan problem çözme becerilerini ölçme ve sonuçlarına göre gerekli planlamaların yapılmasına ihtiyaç vardır. Bu çalışma, hemşirelik öğrencilerinin problem çözme beceri düzeyleri ve etki eden faktörlerin incelenmesi amacıyla yapılmıştır.

\section{YÖNTEM}

Araştırma, hemşirelik öğrencilerinin problem çözme becerilerinin akademik başarı üzerindeki etkisini belirlemek amacıyla tanımlayıcı olarak yapılmıştır. Araştırmanın uygulanabilmesi için, üniversitenin Girişimsel Olmayan Klinik Araştırmalar Etik Kurulu'ndan (No:2015/66), Sağl1k Bilimleri Fakültesi Dekanlığından yazılı izin alınmıştır. Öğrencilere ders sırasında araştırmacılar tarafindan çalışma hakkında sözel bilgilendirme yapılmış ve sözel olarak onamları elde edilmiştir. Çalışmaya dahil olma kriteri olarak gönüllülük esas alınmış, gönüllü olmayan öğrencilerin çalışmaya alınmayacağı açıklanmıştır.

Çalışmanın verileri 2015 yılı bahar döneminde toplanmıştır. Araştırmanın evrenini bir vakıf üniversitesinin hemşirelik bölümünde öğrenim gören toplam 104 öğrenci oluşturmuştur. Katılım oranı \%100'dür. Üniversitenin hemşirelik bölümü yeni açıldığından doları yalnızca bir ve ikinci sınıf bulunmaktadır. Çalışmanın hedefi tüm öğrencilerin problem çözme becerilerini belirlemek olduğu için örneklem seçimine gidilmemiş, çalışmaya katılmayı kabul eden tüm ögrrencilerden veriler toplanmıştır. Öğrenciler, ders sirasında sekiz sorudan oluşan sosyodemografik soru formu ile 35 sorudan oluşan "Problem Çözme Envanteri (PÇE)"ni 15 dakikada doldurmuşlardır.

Problem Çözme Envanteri: Çalışmada kullanılan PÇE Heppner ve Peterson ${ }^{3}$ tarafindan 1982 yılında 
geliştirilmiş olup Cronbach alfa tutarlılık katsayısı 90 bulunmuştur. Ölçek Şahin, Şahin ve Heppner ${ }^{17}$ tarafından 1993 yılında Türkçe'ye uyarlanmış ve oluşan yeni ölçeğin Cronbach alfa tutarlılık katsayısı 0.88 olarak saptanmıştır. PÇE, 35 maddeden

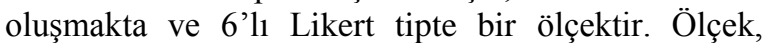
toplam puan (Problem çözme beceri algısı puanı) ve alt ölçeklere ilişkin puanları vermektedir.

Yanıtlanmasında birey, her madde için, hangi sıklıkta o maddelerdeki gibi davrandığını işaretler. Envanterin 6'lı Likert cevaplama seçenekleri: "Her zaman böyle davranırım", "Çoğunlukla böyle davranırım", "Sıı sık böyle davranırım", "Arada sırada böyle davranırım", "Ender olarak böyle davranırım" ve "Hiçbir zaman böyle davranmam" seklindedir. Şahin, Şahin ve Heppner tarafindan yapılan faktör analizi sonucuna göre ölçek; "Aceleci Yaklaşım, Düşünen Yaklaşım, Kaçıngan Yaklaşım, Değerlendirici Yaklaşım, Kendine Güvenli Yaklaşım ve Planlı Yaklaşım" olarak altı faktörden oluşmaktadır. "Envanterin değerlendirilmesinde; verilen cevaplara 1-6 arasında değişen puanlar verilir. Puanlamada 9, 22 ve 29. maddeler puanlama dışı tutulur. Puanlama 32 madde üzerinden yapılır. 1, 2, 3, 4, 11, 13, 14, 15, 17, 21, 25, 26,30 ve 34 . maddeler ters olarak puanlanan maddelerdir. Envanterden alınabilecek puan aralı̆ğ 32-192'dir. Ölçekten alınan toplam puanların yüksekliği, bireyin problem çözme becerileri konusunda kendini yetersiz olarak algıladığını gösterir. Ölçekten alınan toplam puanların azalmasında ise kişinin problem çözme beceri algısının olumlu olduğu kabul edilir. Alt ölçeklerin puanlanmasinda da olumlu istendik olarak nitelendirilebilecek problem çözme yaklaşım biçimlerini ölçen alt ölçeklerden (düşünen yaklaşım, kendine güvenli yaklaşım, değerlendirici yaklaşım, planlı yaklaşım) alınan puanlar azaldıkça ilgili yaklaşım biçimlerinin daha fazla kullanıldığı değerlendirilirken; olumsuz-etkisiz olarak nitelendirilebilecek problem çözme yaklaşım biçimlerini ölçen alt ölçeklerden (aceleci yaklaşım ve kaçıngan yaklaşım) alınan puanlar azaldıkça ilgili yaklaşım biçimlerinin daha az kullanıldığı düşünülür.

Verilerin analizi, SPSS 17.0 paket program kullanılarak sayı, yüzde, aritmetik ortalama, varyans analizi ve iki ortalama arasındaki farkın önemlilik testi ile yapılmıştır. İstatistiksel olarak anlamlılık düzeyi $p<0.05$ olarak kabul edilmiştir.

\section{BULGULAR}

Araştırmaya katılan öğrencilerin sosyo-demografik özellikleri incelendiğinde; yaş ortalaması $19.64 \pm 1.41$, \%51'i ikinci sinıf, \%88.5'i kı, \%44.2'si Anadolu lisesi mezunudur. Öğrencilerin annelerinin \%48.1'i, babalarının \%31.7'si ilkokul mezunu, \%85.6's1 orta düzey gelir durumuna sahip ve \%56.7'si şehirde yaşamaktadır. Öğrencilerin \%57.7'sinin genel akademik başarı puanlarının 2.51 ve üstünde, \%42.3'ünün 2.50 ve altında olduğu belirlenmiştir. Öğrencilerin PÇE genel puan ortalamaları, sınıf, cinsiyet, mezun olunan okul, annenin eğitim durumu, babanın eğitim durumu, gelir durumu, yaşadığı yer ve genel not ortalaması özelliklerine göre karşılaştırıldığında gruplar arasında istatistiksel olarak anlamlı bir farklılık saptanmamışıır ( $>0.05)$ (Tablo $1)$.

Tablo 1. Öğrencilerin ölçek puan ortalamalarının sosyodemografik özelliklerine göre karşılaştırılması

\begin{tabular}{|c|c|c|c|c|c|}
\hline Özellikler & $\mathrm{s}$ & $\%$ & $\begin{array}{c}\text { PÇE } \\
\text { toplam } \\
\text { puanı } \\
\text { Ort } \pm \text { Ss }\end{array}$ & $t / F$ & $P$ \\
\hline $\begin{array}{l}\text { Sinif } \\
1 . \text { Sinıf } \\
\text { 2.Sinıf }\end{array}$ & $\begin{array}{l}51 \\
53\end{array}$ & $\begin{array}{l}49.0 \\
51.0\end{array}$ & $\begin{array}{l}115.5 \pm 15.2 \\
119.1 \pm 19.1\end{array}$ & $t=-1.064$ & .290 \\
\hline $\begin{array}{l}\text { Cinsiyet } \\
\text { Kiz } \\
\text { Erkek }\end{array}$ & $\begin{array}{l}92 \\
12 \\
\end{array}$ & $\begin{array}{l}88.5 \\
11.5 \\
\end{array}$ & $\begin{array}{l}117.6 \pm 17.2 \\
114.8 \pm 19.1\end{array}$ & $\mathrm{t}=.533$ & .595 \\
\hline $\begin{array}{l}\text { Mezun } \\
\text { olunan okul } \\
\text { *SML } \\
\text { Genel lise } \\
\text { Anadolu } \\
\text { Lisesi } \\
\end{array}$ & $\begin{array}{l}14 \\
44 \\
46\end{array}$ & $\begin{array}{l}13.5 \\
42.3 \\
44.2\end{array}$ & $\begin{array}{l}115.2 \pm 15.0 \\
117.7 \pm 17.5 \\
117.3 \pm 17.3\end{array}$ & $\mathrm{~F}=.121$ & .886 \\
\hline $\begin{array}{l}\text { Annenin } \\
\text { Eğitim } \\
\text { Durumu } \\
\text { İlkokul } \\
\text { Ortaokul } \\
\text { Lise } \\
\text { Üniversite }\end{array}$ & $\begin{array}{l}50 \\
26 \\
17 \\
11\end{array}$ & $\begin{array}{l}48.1 \\
25.0 \\
16.3 \\
10.6\end{array}$ & $\begin{array}{l}118.5 \pm 18.4 \\
113.2 \pm 19.7 \\
118.4 \pm 12.9 \\
120.0 \pm 11.5\end{array}$ & $\mathrm{~F}=.675$ & .571 \\
\hline $\begin{array}{l}\text { Babanın } \\
\text { Eğitim } \\
\text { Durumu } \\
\text { İlkokul } \\
\text { Ortaokul } \\
\text { Lise } \\
\text { Üniversite }\end{array}$ & $\begin{array}{l}33 \\
21 \\
28 \\
22 \\
\end{array}$ & $\begin{array}{l}31.7 \\
20.2 \\
26.9 \\
21.2 \\
\end{array}$ & $\begin{array}{l}117.8 \pm 18.2 \\
119.0 \pm 21.3 \\
116.4 \pm 16.0 \\
117.3 \pm 14.1 \\
\end{array}$ & $\mathrm{~F}=.129$ & .942 \\
\hline $\begin{array}{l}\text { Gelir } \\
\text { durumu } \\
\text { Düşük } \\
\text { Orta } \\
\text { Yüksek } \\
\end{array}$ & $\begin{array}{c}5 \\
89 \\
10 \\
\end{array}$ & $\begin{array}{c}4.8 \\
85.6 \\
9.6\end{array}$ & $\begin{array}{l}120.3 \pm 22.0 \\
117.4 \pm 16.9 \\
115.2 \pm 21.7\end{array}$ & $\mathrm{~F}=.122$ & .885 \\
\hline $\begin{array}{l}\text { Yaşadiğı yer } \\
\text { Şehir } \\
\text { Ilcçe } \\
\text { Köy } \\
\end{array}$ & $\begin{array}{l}59 \\
30 \\
15 \\
\end{array}$ & $\begin{array}{l}56.7 \\
28.8 \\
14.4 \\
\end{array}$ & $\begin{array}{l}119.1 \pm 15.9 \\
114.6 \pm 19.8 \\
115.7 \pm 17.6 \\
\end{array}$ & $\mathrm{~F}=.746$ & .477 \\
\hline $\begin{array}{l}\text { Genel not } \\
\text { ortalaması } \\
2.50 \text { ve altı } \\
2.51 \text { ve üstü }\end{array}$ & $\begin{array}{l}44 \\
60\end{array}$ & $\begin{array}{l}42.3 \\
57.7\end{array}$ & $\begin{array}{l}119.5 \pm 17.3 \\
115.7 \pm 17.3\end{array}$ & $\mathrm{t}=1.091$ & .278 \\
\hline
\end{tabular}

Hemşirelik öğrencilerinin PÇE genel puan ortalaması 117.3 \pm 17.3 olarak belirlenmiştir. Ölçeğin alt boyutlarından alınan puan ortalamaları ise; aceleci

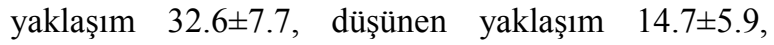
kaçıngan yaklaşım $15.8 \pm 4.8$, değerlendirici yaklaşım $8.9 \pm 4.0$, kendine güven $22.8 \pm 5.3$, planlı yaklaşım 11.6 \pm 4.8 puan olarak belirlenmiştir (Tablo 2). PÇE genel puan ortalamas1 ve alt boyut puan ortalamaları değerlendirildiğinde, öğrencilerin kendilerini orta düzeyde problem çözme becerisine sahip olarak algıladıkları belirlenmiştir. 


\section{TARTIŞMA}

Hızla gelişen teknolojiler, modern hastane ortamları ve kompleks sağlık bakım uygulamaları arasında hemşirelerin başarılı olabilmesi, sürekli bakım gereksinimleri olan hastalara güvenli ve etkili bakım verebilmesi, yüksek düzey eleştirel düşünme ve problem çözme becerisi gerektirir.

Tablo 2. Hemşirelik öğrencilerinin problem çözme ölçeğinden aldıkları puan ortalamalarının dağılımı

\begin{tabular}{lccc}
\hline Ölçek alt boyutları & $\begin{array}{c}\text { Puan Aralığ1 } \\
\text { (Min-Max) }\end{array}$ & Ort. & Ss \\
\hline Genel Puan & $32-192$ & 117.3 & 17.3 \\
Aceleci Yaklaşım & $9-54$ & 32.6 & 7.7 \\
Kaçıngan Yaklaşım & $4-24$ & 15.8 & 4.8 \\
Düşünen Yaklaşım & $5-30$ & 14.7 & 5.9 \\
Değerlendirici & $3-18$ & 8.9 & 4.0 \\
Yaklaşım & & 22.8 & 5.3 \\
Kendine Güven & $6-36$ & 11.6 & 4.8 \\
Planlı Yaklaşım & $4-24$ & & \\
\hline
\end{tabular}

Çalışma sonuçlarımıza göre; hemşirelik öğrencilerinin PÇE'den aldıkları toplam puan ortalaması ile alt boyutlardan aldıkları puan ortalamaları problem çözme becerilerinin orta düzeyde olduğunu göstermiştir. Bu sonucu destekler yönde olan birçok çalışmada öğrencilerin problem çcözme beceri puan ortalamalarının orta düzey olduğu bildirilmiştir. ${ }^{1,2,5-}$ 7,10,18-22 $\mathrm{Bu}$ çalışmalardan farkl olarak Şahiner ve ark. $^{23}$ çalışmasında öğrenci hemşirelerin PÇE puan ortalaması düşük çıktığı için problem çözme beceri algılarını yeterli olarak değerlendirmiştir. Bir başka çalışmada ise vakaya dayalı öğrenmenin problem çözmeye etkisi araştırılmış, vakaya dayalı öğrenme grubu ile klasik ders grubunda yer alan hemşirelik öğrencilerinin problem çözme puan ortalamalarının benzer ve orta düzeyde olduğu bulunmuş, ancak eğitimden sonra vakaya dayalı öğrenme grubunun problem çözme becerisinin arttığı belirlenmiştir. ${ }^{13}$

Çalışmamızda, hemşirelik öğrencilerinin problem çözme becerilerinin sınıf, cinsiyet, mezun olunan okul annenin ve babanın eğitim durumu, ailenin gelir durumu ve öğrencinin yaşadığı yer ve akademik başarı puanlarına göre aralarında istatistiksel olarak fark olmadığı belirlenmiştir. Bu sonuç literatürde yer alan bazı çalışma sonuçları ile benzerlik göstermektedir. Hemşirelik öğrencilerinin problem çözme beceri seviyelerinin araştırıldığı bir çalışmada öğrencilerin problem çözme becerisinin bölüm, cinsiyet, yaş, anne-baba eğitim düzeyi ve problem çözme ile ilgili eğitim alma durumu değişkenlerine göre anlamlı bir farklılık göstermediği belirlenmiştir. ${ }^{22}$ Yıldırım, Özkahraman ve Sarıkaya, ${ }^{19}$ 250 hemşire ve 173 ebelik öğrencisi ile yaptıkları çalışmada, öğrencilerin problem çözme becerilerinin yaş, bölüm, mezun oldukları lise türüne göre fark olmadığını belirlemişlerdir. Hemşirelik öğrencileri ile yapılan başka bir araştırmada, öğrencilerin problem çözme becerilerinin cinsiyet, sınıf, mezun olunan okul, üniversite yaşantılarında kaldıkları yer, anne ve baba yaklaşımlarının problem çözme beceri ortalamalarını etkilemediği belirlenmiştir. ${ }^{20}$ Elkin ve Karadağ $l 1,{ }^{2}$ sağlık bilimleri yüksekokulunda öğrenim gören 596 öğrenci ile yaptıkları çalışmada öğrencilerin cinsiyetine, eğitim gördükleri bölüme, sınıfına, bitirdiği lise türüne, çocukluğunu geçirdiği yerleşim birimine, gelir düzeyine, anne ve babanın eğitim düzeyine, aile tipine, kardeş varlığına, ebeveyn çocuk yetiştirme tarzına, akademik başarı algısına, hobi varlığ ile problem çözme eğitimi alma durumu değişkenlerine göre farklılık olmadığını belirlemişlerdir. Kanbay ve ark. ${ }^{18}$ yaş, cinsiyet ve sınıf düzeyleri ile öğrencilerin problem çözme becerileri arasında anlamlı bir fark saptamamışlardır. Ilıman çalışmasında; yaş, mezun olunan lise, gelir düzeyi, sınıf düzeyi, üniversite, bilgisayar ve yabancı dil eğitimine göre ile PÇE puan ortalaması arasında istatistiksel olarak anlamlı fark olmadığını belirlemiştir. $^{24}$

Öğrencilerin problem çözme becerileri üzerine bazı sosyodemografik özelliklerin etkili olduğunu ortaya koyan çalışmalar da mevcuttur. Koç ve ark. çalışmalarında, hemşirelik bölümünde okuyan, sağlık meslek lisesi mezunu, çekirdek aile yapısına sahip erkek öğrencilerin problem çözme becerilerinin diğer öğrencilerden daha yüksek olduğunu saptamışlardır. ${ }^{5}$ Günüşen ve Üstün, problem çözme becerisinin dördüncü sınıf öğrencilerinde en yüksek, birinci sınıf öğrencilerinde ise en düşük olduğunu ve sınıf düzeyi yükseldikçe problem çözme becerisinin arttığını saptamıştır. ${ }^{1}$ Hemşirelik öğrencileri ile yapılan bir çalışmada kız öğrencilerin, aile yapısı demokratik, anne eğitim düzeyi lise olan öğrencilerin problem çözme algısının yüksek olduğu belirlenmiştir. ${ }^{24}$ Olgun ve ark. ${ }^{7}$ cinsiyet, öğrencilerin geldikleri yer ve hobiye sahip olma durumunun problem çözme becerisini etkilemediğini ancak yurtta kalan öğrencilerin problem çözme becerilerinin daha iyi olduğunu ayrıca not ortalaması yüksek olan öğrencilerin yaklaşmakaçınma ve kişisel kontrol alt boyutlarında problem çözme becerilerinin daha iyi olduğunu belirlemiştir. Kim ve $\mathrm{Choi}^{10}$ lisans eğitimi alan, kişilerarası iletişimi iyi olan ve hemşirelik mesleğinden memnun olan öğrencilerin problem çözme beceri puanlarının daha iyi olduğunu saptamışlardır. Problem çözme becerisi öğrenilebilir, geliştirilebilir ve birçok faktörden de etkilenen bir beceridir. Bu nedenle yapılan çalışma sonuçlarında öğrencilerin problem çözme becerilerine etki eden faktörlerin farklılık göstermesi beklenen bir durum olarak açıklanabilir.

\section{Araştırmanın Sınırlılıkları}

$\mathrm{Bu}$ çalışma hemşirelik bölümünün yeni açılmış olması nedeniyle yalnızca bir ve ikinci sinıfları kapsadığından araştırma sonuçlarının tüm hemşirelik öğrencilerine genellenemez. 


\section{SONUÇ}

Elde edilen veriler sonucunda, bu çalışmadaki hemşirelik öğrencilerinde problem çözme becerilerinin orta düzeyde olduğu, sosyo-demografik özelliklere göre problem çözme beceri düzeyleri arasında fark olmadığı saptanmıştır. Bu bağlamda öğrencilerin problem çözme becerilerinin geliştirilmesinde etkili olacak vaka/proje/probleme dayalı öğrenme yöntemleri gibi interaktif öğrenme yöntemlerinin kullanılması, araştırmacılar için problem çözme becerisini arttırmada etkili olacak yöntemlerin uygulanarak bunların etkisini ortaya koyan çalışmaların yapılması önerilmektedir.

\section{KAYNAKLAR}

1. Günüşen NP, Üstün B. Hemşirelik öğrencilerinin problem çözme beceri düzeyleri ile kontrol odağ1 arasındaki ilişki. Dokuz Eylül Üniversitesi Hemşirelik Yüksekokulu Elektronik Dergisi. 2011;4(2):72-77.

2. Elkin N, Karadağlı F. Üniversite öğrencilerinin problem çözme becerilerinin değerlendirilmesi. Adiyaman Üniversitesi Sağllk Bilimleri Dergisi. 2015;1:11-18.

3. Heppner PP, Petersen CH. The development and implications of a personal problem-solving inventory. J Couns Psychol. 1982;29(1):66-75.

4. Oğuz V. Akyol AA. Problem çözme ölçeği geçerlilik ve güvenirlilik çalışması. Çukurova Üniversitesi Eğitim Bilimleri Dergisi. 2015;44(1):105-122.

5. Koç Z, Koyuncu S, Sağlam Z. Sağlık yüksekokulu hemşirelik ve ebelik öğrencilerinin problem çözme beceri düzeyleri ve etkileyen faktörler. HEAD. 2015;12(1):41-50.

6. Kantek F, Öztürk N, Gezer N. Bir Sağlık yüksekokulunda öğrencilerin eleştirel düşünme ve problem çözme becerilerinin incelenmesi. International Conference on New Trends in Education and Their Implications-ICONTE. 2010:186-190.

7. Olgun N, Öntürk ZK, Karabacak Ü, Aslan FE, Serbest Ş. Hemşirelik öğrencilerinin problem çözme becerileri: bir yıllık izlem sonuçları. Acıbadem Üniversitesi Sağlık Bilimleri Dergisi. 2010;1:188-195.

8. Yıldırım B, Özkahraman Ş. Hemşirelikte problem çözme. S.D. Ü. Sağllk Bilimleri Enstitüsü Dergisi. 2011;2(3):155-160.

9. Can HÖ, Öner Öİ, Çelebi E. Üniversite öğrencilerinde eğitimin sorun çözme becerisine etkisinin incelenmesi. Firat Sağllk Hizmetleri Dergisi. 2009;4:36-58.

10. Kim KS, Choi JH. The relationship between problem solving ability, professional self concept, and critical thinking disposition of nursing students. International Journal of Bio-Science and Bio-Technology. 2014;6(5):131-142.

11. Kantek F, Kartal H. A meta analysis: The problem solving skills of nursing and other bachelor students. Journal of Educational and Instructional Studies In The World. 2016;6:121-128.

12. Lee MB, Brysiewicz P. Enhancing problem solving and nursing diagnosis in year III bachelor of nursing students. Nurse Educ Today. 2009;29:389-397.

13. Yoo MS, Park JH. Effect of case-based learning on the development of graduate nurses' problemsolving ability. Nurse Educ Today. 2014;34:4751.

14. Kaddoura MA. Critical thinking skills of nursing students in lecture-based teaching and case-based learning. International Journal for the Scholarship of Teaching and Learning. 2011;5(2),1-18.

15. Sprang SM. Making the case: using case studies for staff development. $J$ Nurs Staff Dev. 2010;26(2):E6-E10.

16. Ançel G. Problem-solving training: effects on the problem-solving skills and self-efficacy of nursing students. Eurasian Journal of Educational Research. 2016;64:231-246.

17. Şahin NH, Şahin N, Heppner P. Psychometric properties of the problem solving inventory in a group of Turkish university students. Cognitive Ther Res. 1993;17(3):379-385.

18. Kanbay Y, Aslan Ö, Işık E, Kılıç N. Hemşirelik lisans öğrencilerinin problem çözme ve eleştirel düşünme becerileri. Yükseköğretim ve Bilim Dergisi. 2013;3(3):244-251.

19. Yıldırım B, Özkahraman ŞK, Sarıkaya SK. Hemşirelik ve ebelik öğrencilerinin problem çözme becerileri ile öğrenme biçemleri arasındaki ilişkinin incelenmesi. Gümüşhane Üniversitesi Sağllk Bilimleri Dergisi. 2014;3(3):859-882.

20. Yüksel A. Hemşirelik öğrencilerinin problem çözme öz değerlendirme sonuçları ve etkileyen faktörler araştırma. Hacettepe Üniversitesi Hemşirelik Fakültesi Dergisi. 2015;37-49.

21. Karabulutlu EY, Yılmaz S., Yurttaş A. Öğrencilerin duygusal zeka düzeyleri ile problem çözme becerileri arasındaki ilişki. Psikiyatri Hemşireliği Dergisi. 2011;2 (2),75-79.

22. Yılmaz E, Karaca F, Y1lmaz E. Sağlık yüksekokulu öğrencilerinin problem çözme becerilerinin bazı değişkenler açısından incelenmesi. Atatürk Üniversitesi Hemşirelik Yüksekokulu Dergisi. 2009;12(1):38-48.

23. Şahiner G, Açıksöz S, Açıkel C. Hemşirelik yüksekokulu öğrencilerinin problem çözme becerilerinin incelenmesi. TAF Prev Med Bull. 2013;12(6):673-680.

24. Ilıman AY. Klasik ve Entegre Eğitim Modeli ile Ögrrenim Gören Hemşirelik Öğrencilerinde Problem Çözme Becerisi ve Yaşam Boyu Ögrenme Ĕgilimi. Marmara Üniversitesi Sağlık Bilimleri Enstitüsü Yüksek Lisans Tezi, 2017. 